\title{
Diferentes tipos de ambiente protegido e substratos na produção de pimenteiras
}

\author{
Edilson Costa ${ }^{1}$; Tiago LE Santo ${ }^{2}$; Thiago B Batista ${ }^{1}$; Thayla MRC Curi ${ }^{3}$
}

${ }^{1}$ Universidade Estadual de Mato Grosso do Sul (UEMS), Cassilândia-MS, Brasil; mestrine@uems.br; mestrine.uems@gmail.com; batistatb@ hotmail.com; ${ }^{2}$ Universidade Estadual de Mato Grosso do Sul (UEMS), Aquidauana-MS, Brasil; tiagropec@hotmail.com; ${ }^{3}$ Universidade Estadual de Campinas (UNICAMP), Campinas-SP, Brasil; thaylamrcarvalho@hotmail.com

\section{RESUMO}

O valor comercial da cultura da pimenta aumentou para uso ornamental e alimentício, necessitando do aprimoramento de técnicas de cultivos como o tipo de ambiente protegido e substratos de baixo custo. Assim, o objetivo foi avaliar parâmetros de emergência e crescimento de mudas em bandeja, bem como crescimento de plantas e produção em vasos de cultivares de pimenteiras Tupã Bode Vermelha, Boyra Habanero Vermelha e cultivares de pimenteiras ornamentais Etna e Pirâmide em três ambientes protegidos e seis substratos. Os três ambientes protegidos foram: 1) estufa agrícola com filme de polietileno de baixa densidade transparente e tela termo refletora sob o filme; 2) viveiro agrícola, telado de mono filamento de cor preta e; 3 ) viveiro agrícola, com tela termo refletora aluminizada. Foram avaliados os substratos: a) $1 / 2 \mathrm{E}$ (esterco bovino) $+1 / 2 \mathrm{H}$ (húmus); b) $1 / 2 \mathrm{E}+1 / 2 \mathrm{~V}$ (vermiculita); c) $1 / 2 \mathrm{E}+1 / 2 \mathrm{R}$ (rama de mandioca); d) $1 / 3 \mathrm{E}+1 / 3 \mathrm{H}+1 / 3 \mathrm{~V}$; e) $1 / 3 \mathrm{E}+1 / 3 \mathrm{H}+1 / 3 \mathrm{R}$ e f) $1 / 4 \mathrm{E}+1 / 4 \mathrm{H}+1 / 4 \mathrm{~V}+1 / 4 \mathrm{R}$. Cada ambiente protegido foi considerado um experimento os quais foram comparados pela análise conjunta. Para as cultivares Etna, Pirâmide, Tupã e Boyra o uso dos substratos $1 \frac{1}{2} \mathrm{E}+1 / 2 \mathrm{R}, 1 / 3 \mathrm{E}+1 / 3 \mathrm{H}+1 / 3 \mathrm{R}$ e $1 / 3 \mathrm{E}+1 / 3 \mathrm{H}+1 / 3 \mathrm{~V}$ possibilitaram maior diâmetro de colo, altura de planta e índice de qualidade de Dickson na fase de formação de mudas, enquanto que o número de frutos foi superior com a utilização dos substratos $1 / 2 \mathrm{E}+1 / 2 \mathrm{R}$ e $1 / 3 \mathrm{E}+1 / 3 \mathrm{H}+1 / 3 \mathrm{~V}$. O ambiente protegido de estufa foi o mais adequado para todas as cultivares, seguido pelo sombrite ${ }^{\circledR}$ (Tupã e Boyra) e aluminet ${ }^{\circledR}$ (Pirâmide).

Palavras-chave: Capsicum frutescens, esterco bovino, ramas de mandioca, húmus, vermiculita, produtividade.

\begin{abstract}
Different type of greenhouse and substrata on pepper production

Pepper production has great commercial value for ornamental and food use. This makes it necessary to improve cultivation techniques, such as environmental control and low cost substrata. Therefore, this study aimed to evaluate the emergence parameters and growth of seedlings in tray, as well as plant growth and production in pots of pepper cvs. Tupã Bode Vermelha and Boyra Habanero Vermelha and ornamental pepper cultivars Etna and Pirâmide, in three different types of greenhouse and six types of substrata. Three greenhouses were evaluated: 1) a greenhouse with low-density transparent polyethylene film and reflective aluminized screen under the film; 2) sombrite ${ }^{\circledR}$ mono black filament with $50 \%$ shade; and 3) aluminet ${ }^{\circledR}$, reflective aluminized screen. In these environments we tested six substrata a) $1 / 2$ cattle manure $(\mathrm{E})$ and $1 / 2$ humus $(\mathrm{H}) ; \mathrm{b}) 1 / 2 \mathrm{E}$ and $1 / 2$ vermiculite $(\mathrm{V})$; c) $1 / 2 \mathrm{E}$ and $1 / 2$ cassava's leaves (R); d) $1 / 3 \mathrm{E}+1 / 3 \mathrm{H}+1 / 3 \mathrm{~V}$; e) $1 / 3 \mathrm{E}+1 / 3 \mathrm{H}+1 / 3 \mathrm{R}$ and f) $1 / 4 E+1 / 4 H+1 / 4 V+1 / 4 R$. Since no replication of cultivation was carried out, each environment was considered as one experiment. The use of substrata $1 / 2 E+1 / 2 R ; 1 / 3 E+1 / 3 H+1 / 3 R$ and $1 / 3 E+1 / 3 H+1 / 3 V$ allowed greater stem diameter, plant height and Dickson quality index in seedling stage of cultivars Etna, Pirâmide, Tupã and Boyra. The number of fruit was higher with the use of the substrata $1 / 2 \mathrm{E}+1 / 2 \mathrm{R}$ and $1 / 3 \mathrm{E}+1 / 3 \mathrm{H}+1 / 3 \mathrm{~V}$. The most suitable environment for pepper production is the greenhouse for all cultivars, followed by sombrite ${ }^{\mathbb{R}}$ (especially for cultivars Tupã and Boyra) and aluminet ${ }^{\mathbb{B}}$ (Pirâmide).
\end{abstract}

Keywords: Capsicum frutescens, cattle manure, cassava's leaves, humus, vermiculite, productivity.

\section{(Recebido para publicação em 15 de fevereiro de 2016; aceito em 30 de dezembro de 2016) (Received on February 15, 2016; accepted on December 30, 2016)}

$\mathrm{O}$ cenário da produção de cultivares de pimenteiras se apresenta promissor em função do aumento do consumo para uso alimentício e ornamental, e por esta razão faz-se necessário o aprimoramento do sistema de produção.

A produção de pimenteiras do gênero Capsicum apresenta crescimento considerável no agronegócio brasileiro em função de sua rentabilidade, empregabilidade, e principalmente pela apreciação na alimentação, na indústria farmacêutica e como planta ornamental (Silva Neto et al., 2014). Os frutos provenientes de Capsicum spp. são fontes importantes de antioxidantes naturais, tais como vitamina $\mathrm{C}$, carotenoides e vitamina E (Rêgo et al., 2012).

O desafio da produção agropecuária em países de clima tropical e subtropical, como o Brasil, é em decorrência das temperaturas elevadas que interferem na cultura, fazendo com que produtores optem pelo uso de ambientes protegidos. Neste contexto, a utilização de ambiente 
protegido na produção de pimenta auxilia no controle das condições ambientais bem como na questão hídrica. Recomenda-se o cultivo em ambiente protegido, em regiões com altas temperaturas, excesso de radiação e períodos longos de chuvas, visando reduzir danos causados nos tecidos celulares de plantas em estado juvenil por estas intempéries climáticas. Ainda, auxilia no manejo da cultura, promovendo melhores condições para o desenvolvimento da planta, aumento da produtividade (produção na entressafra) e qualidade, por consequência, a rentabilidade (Rêgo et al., 2012).

A etapa mais critica na produção final da pimenteira consiste na produção de mudas, pois essa exerce influência no desempenho final da planta, tanto do ponto de vista nutricional como do produtivo, visto que há uma relação direta entre mudas sadias e produção a campo; já o substrato influência a arquitetura do sistema radicular e o estado nutricional da planta (Finger $e t$ al., 2012). Mudas bem formadas podem incrementar a produção, enquanto que aquelas mal formadas podem ampliar o ciclo da cultura e, consequentemente, causar prejuízos ao produtor (Guimarães et al., 2002).

Dessa forma, a escolha do substrato adequado, empregando em sua composição matéria prima de baixo custo com boas propriedades químicas e físicas, auxilia positivamente na germinação das sementes e desenvolvimento das plântulas. Entretanto, a utilização de apenas um substrato contendo todas as características necessárias é desafiador; por isso há a necessidade da união de vários materiais para produção de um único substrato. Assim, o sucesso na produção de pimenteiras, está em função do ambiente protegido e do substrato escolhido.

Visando o conjunto, ambiente protegido e sistema de cultivo de hortaliças, os substratos vêm sendo muito pesquisados para obtenção do melhor acondicionamento ao sistema radicular e ao crescimento e desenvolvimento das plântulas. Vários autores relatam a importância da escolha de substratos adequados para a produção de mudas de hortaliças. O papel fundamental da pesquisa é identificar as melhores combinações de substratos, utilizando dois ou mais materiais, de origem orgânica, mineral ou sintética, procurando atender a exigências de cada espécie (Silva Neto et al., 2014; Oliveira et al., 2014).

Os substratos comerciais são os mais utilizados para a produção de pimenteiras ornamentais (Finger et al., 2012). Entretanto, sabe-se que substratos orgânicos promovem melhores níveis de oxigênio nas raízes que alguns substratos minerais, com uma boa aeração. Ao decompor a matéria orgânica presente no material, de forma gradativa, fornecem os nutrientes na quantidade que a planta necessita, para seu crescimento e produção, sem causar lixiviação. Para os produtores, esses substratos minimizam custos de produção, pois muitas vezes são obtidos no próprio local (Gomes et al., 2003). Em pimenteiras existem estudos utilizando o lodo de curtume (Silva et al., 2011), o vermicomposto, fibra de coco e húmus de minhoca e composto orgânico à base de folhas de figueira (Ficus elastica), parte aérea de grama (Paspalum notatum) e esterco bovino; estudos esses que visaram avaliar a germinação e/ou o desenvolvimento inicial de mudas.

Diante do exposto, o objetivo foi avaliar parâmetros de emergência e crescimento de mudas em bandeja, bem como crescimento de plantas e produção em vasos de cultivares de pimenteiras Tupã e Boyra e as ornamentais Etna e Pirâmide, em três ambientes protegidos e seis substratos.

\section{MATERIAL E MÉTODOS}

O presente trabalho foi conduzido no setor de Horticultura da Universidade Estadual de Mato Grosso do Sul, Unidade Universitária de Aquidauana, no período de janeiro a maio do ano de 2012. Foi usado delineamento inteiramente casualizado com vinte e quatro tratamentos, sendo seis subtratos e quatro cultivares de pimenteiras: Tupã Bode Vermelha, Boyra Habanero Vermelha e as ornamentais Etna e Pirâmide. Esses experimentos foram realizados em três ambientes de cultivo e em duas fases: formação de mudas e produção de frutos, sendo usadas oito repetições de cinco plântulas na fase de mudas em bandeja e dez repetições (vaso) na fase de produção no vaso.

Os substratos utilizados foram: a) $50 \%$ esterco bovino $+50 \%$ húmus $(1 / 2 \mathrm{E}+1 / 2 \mathrm{H})$; b) $50 \%$ esterco bovino + $50 \%$ vermiculita $(1 / 2 \mathrm{E}+1 / 2 \mathrm{~V})$; c) $50 \%$ esterco bovino $+50 \%$ rama de mandioca $(1 / 2 \mathrm{E}+1 / 2 \mathrm{R}) ; \mathrm{d}) 33,3 \%$ esterco bovino $+33,3 \%$ húmus $+33,3 \%$ vermiculita $(1 / 3 \mathrm{E}+1 / 3 \mathrm{H}+1 / 3 \mathrm{~V})$; e) $33,3 \%$ esterco bovino $+33,3 \%$ húmus $+33,3 \%$ ramas de mandioca $(1 / 3 \mathrm{E}+1 / 3 \mathrm{H}+1 / 3 \mathrm{R})$; e f) $25 \%$ esterco bovino $+25 \%$ húmus $+25 \%$ vermiculita $+25 \%$ ramas de mandioca $(1 / 4 \mathrm{E}+1 / 4 \mathrm{H}+1 / 4 \mathrm{~V}+1 / 4 \mathrm{R})$.

Os ambientes protegidos foram: 1$)$ estufa agrícola em arco $(8 \times 18 \times 4 \mathrm{~m})$ de estrutura em aço galvanizado, com abertura zenital na cumeeira, coberta com filme difusor de luz de polietileno de baixa densidade de $150 \mu \mathrm{m}$ de espessura, possuindo tela termo refletora aluminizada de $50 \%$ de sombreamento sob o filme e fechamentos laterais e frontais com tela de monofilamento na cor preta de $50 \%$ de sombreamento (estufa); 2) viveiro agrícola telado, de estrutura em aço galvanizado $(8,0 \times 18,0 \times 3,5 \mathrm{~m})$, fechamento em $45^{\circ}$ de tela de monofilamento na cor preta de $50 \%$ de sombreamento (sombrite ${ }^{\circledR}$ ) e 3) viveiro agrícola telado, de estrutura em aço galvanizado $(8,0 \times 18,0 \times 3,5$ $\mathrm{m})$, fechamento em $45^{\circ}$ de tela termo refletora aluminizada com $50 \%$ de sombreamento (aluminet ${ }^{\circledR}$ ).

\section{Obtenção e caracterização dos substratos}

As ramas de mandioca foram trituradas em moinho de martelo, utilizando peneira de $8 \mathrm{~mm}$, e posteriormente as mesmas foram colocadas para compostagem por 72 dias, sendo molhadas diariamente e reviradas a cada dois dias. O esterco bovino, obtido de frigorífico da região de Aquidauana-MS com mistura de material de curral e do rumem dos animais, foi compostado por 72 dias. $\mathrm{O}$ húmus de minhoca foi obtido da empresa sediada no município de Dois Irmãos do Buriti-MS, com material de alimentação das minhocas sendo água residuária 
de frigorífico e esterco bovino. Foi utilizada vermiculita comercial de textura classificada como superfina. A irrigação foi realizada manualmente com regador, duas vezes ao dia quando necessária. Após a compostagem dos materiais, os mesmos foram submetidos à análise química que apresentaram as seguintes características de $\mathrm{N}, \mathrm{P}, \mathrm{K}, \mathrm{Ca}$, $\mathrm{Mg}, \mathrm{S}, \mathrm{C}$, matéria orgânica $(\mathrm{g} / \mathrm{kg})$, de $\mathrm{Cu}, \mathrm{Zn}, \mathrm{Fe}, \mathrm{Mn}, \mathrm{B}$ $(\mathrm{mg} / \mathrm{kg})$ e de $\mathrm{pH}$, umidade e relação carbono/nitrogênio, respectivamente: esterco bovino $(10,60 ; 3,66 ; 1,00 ; 9,80$; 1,$65 ; 1,81 ; 96,50 ; 166,00 ; 17,50 ; 75,00$; 7800,$00 ; 310,00 ; 11,47 ; 6,50 ; 2,86$; $15,66)$; ramas de mandioca $(19,50$; 2,$89 ; 7,00 ; 18,80 ; 6,15 ; 2,42 ; 376,00$; 647,$00 ; 20,50 ; 87,50 ; 3440,00 ; 520,00$; $20,70 ; 7,20 ; 11,23 ; 19,50)$ e húmus de minhoca $(14,80 ; 4,46 ; 1,00 ; 26,70$; 12,$50 ; 3,53 ; 163,00 ; 281,00 ; 30,00$; 130,$00 ; 14800,00 ; 370,00 ; 14,40 ; 6,90$; $13,46 ; 11,01)$.

\section{Formação de mudas em bandejas}

As mudas foram produzidas em bandejas de poliestireno expandido de 128 células $(3,5 \mathrm{~cm}$ de largura por 6,2 $\mathrm{cm}$ de altura e volume de $34,6 \mathrm{~cm}^{3}$ por célula), preenchidas com os substratos citados anteriormente.

A semeadura ocorreu no dia 05 de janeiro de 2012. As avaliações na formação de mudas tiveram início cinco dias após a semeadura, sendo realizada a contagem das plantas emergidas diariamente, onde a mesma se estendeu até a estabilização de um dos tratamentos. Isso ocorreu aos 15 dias após a semeadura, quando os valores das contagens de plantas emergidas começou a se repetir nas últimas três coletas e nessa etapa foi avaliado o índice de velocidade (IVE).

As avaliações das mudas ocorreram aos 28 dias (quando as plantas apresentavam de quatro a cinco folhas definitivas), e posteriormente foram mensurados os parâmetros de altura de planta (AP), diâmetro do colo (DC), as fitomassas das matérias secas da parte aérea (MSPA) e do sistema radicular (MSSR). A secagem da fitomassa foi realizada em estufa com circulação forçada de ar, a $65^{\circ} \mathrm{C}$ por 72 horas.
Somaram-se as MSPA e MSSR para obtenção da fitomassa da matéria seca total (MST). Foi determinado o índice de qualidade de Dickson (IQD):

$$
I Q D=\frac{M S T}{\frac{A P}{D C}+\frac{M S P A}{M S S R}}
$$

Variáveis ambientais de temperatura (Tbs, ${ }^{\circ} \mathrm{C}$ ) e umidade relativa (UR, \%) foram mensuradas por meio de um termohigrógrafo (modelo THDL-400, marca Instrument ${ }^{\mathbb{R}}$ ) diariamente às 09 , 12 e $15 \mathrm{~h}$, no ambiente interno e externo das instalações no período entre os dias 05 de janeiro e 07 de fevereiro 2012. No ambiente interno os equipamentos foram posicionados nas bancadas nas três instalações avaliadas, enquanto no meio externo o equipamento estava instalado em um esteio de madeira a 1,20 m do solo. Posteriormente, a umidade relativa do ar foi determinada com auxílio do programa Psychrometric Function Demo ${ }^{\circledR}$. Os valores das variáveis ambientais de Tbs e UR dos ambientes 1), 2), 3) e externo, foram: 1) estufa $(28,63 ; 32,47 ; 32,54 ; 74,56$; $60,50 ; 59,90) ; 2)$ sombrite $(29,28 ; 33,44$; $34,99 ; 70,66 ; 51,06 ; 53,03) ; 3$ ) aluminet $(28,29 ; 32,65 ; 33,67 ; 77,13 ; 62,73$; $58,41)$ e externo $(28,36 ; 32,73 ; 33,94$; $74,88 ; 61,75 ; 59,11)$.

\section{Produção dos frutos em vasos}

Nessa fase experimental foram utilizados os mesmos ambientes e substratos, excetuando o substrato $50 \%$ de ramas de mandioca $+50 \%$ de húmus $(\mathrm{M}+\mathrm{H})$, onde houve elevada mortalidade das mudas. Foram utilizados vasos de 5,0 L. A irrigação foi realizada manualmente com regador, duas vezes ao dia quando necessária.

O transplante para o vaso ocorreu no dia 08 de fevereiro de 2012, quando as plantas apresentavam de quatro a cinco folhas definitivas. As cultivares de pimenta ornamental foram conduzidas verticalmente em haste única utilizando barbante para o tutoramento, sendo cultivada uma planta por vaso. Foi mensurado o número de frutos por planta (NFP) e produção por planta (PP). Os frutos foram colhidos no período entre 27 de abril e 27 de maio de 2012.
Durante a fase de produção dos frutos foram verificadas incidência de pragas como pulgão, mosca branca e larva minadora, sendo realizado o tratamento fitossanitário adequado com produtos registrados.

Foram mensuradas diariamente variáveis ambientais Tbs e UR às 9,12 e $15 \mathrm{~h}$, em cada ambiente de cultivo e no ambiente externo, no período entre 08 de fevereiro e 27 de maio de 2012. Posteriormente, a umidade relativa do ar foi determinada pelo programa Psychrometric Function Demo ${ }^{\circledR}$. Os valores das variáveis ambientais de Tbs e UR dos ambientes 1), 2), 3) e externo, foram: 1$)$ estufa $(28,08 ; 31,58 ; 30,55$; $70,62 ; 59,39 ; 63,90) ; 2)$ sombrite $(28,76$; $32,61 ; 32,27 ; 65,87 ; 54,50 ; 55,89) ; 3)$ aluminet $(27,18 ; 31,13 ; 30,55 ; 73,70$; $61,34 ; 64,48)$ e externo $(27,18 ; 31,51$; $30,91 ; 71,86 ; 60,00 ; 62,20)$.

\section{RESULTADOS E DISCUSSÃO}

Para a cultivar Etna, a relação entre o maior e o menor quadrado médio do resíduo (RQMR) das análises individuais (substratos) dos três ambientes de cultivo (experimentos) para as variáveis altura da planta (AP), fitomassa da matéria seca do sistema radicular (MSSR), fitomassa da matéria seca da parte aérea (MSPA), fitomassa da matéria seca total (MST), índice de qualidade de Dickson (IQD), foi verificado que a RQMR foi maior que 7, não permitindo a comparação dos ambientes de cultivo destas variáveis pela análise conjunta (Banzatto \& Kronka, 2013). Para as demais variáveis, índice de velocidade (IVE), diâmetro do colo (DC), número de frutos por planta (NFP) e produção por planta (PP) a RQMR foi menor que 7 , permitindo a comparação dos ambientes. Para todas as variáveis que permitiram a análise conjunta, houve interação entre ambientes e substratos.

Para a cultivar Pirâmide, nas análises individuais (substratos) dos três ambientes de cultivo (experimentos), todas as variáveis (IVE, AP, DC, MSPA, MSSR, MST, IQD, NFP e PP) apresentaram RQMR menor que 7, permitindo, portanto a análise conjunta e comparação dos ambientes de cultivo 
Tabela 1. Ambientes e substratos na fase de produção das mudas em bandejas e de produção de frutos em vasos de pimenteira em bandejas, cultivar Etna (environments and substrates during seedlings and fruit production phase for pepper production, cv. Etna). Aquidauana, UEMS, 2012.

\begin{tabular}{|c|c|c|c|c|c|c|}
\hline \multirow{2}{*}{ Substratos ** } & \multicolumn{3}{|c|}{ Índice de velocidade de emergência } & \multicolumn{3}{|c|}{ Diâmetro do colo (mm) } \\
\hline & Estufa & Sombrite ${ }^{\circledR}$ & Aluminet $\AA$ & Estufa & Sombrite ${ }^{\circledR}$ & 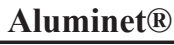 \\
\hline $1 / 2 \mathrm{E}+1 / 2 \mathrm{H}$ & $9,8 \mathrm{bA}^{*}$ & $5,6 \mathrm{bC}$ & $7,4 \mathrm{bB}$ & $1,51 \mathrm{bA}$ & $1,12 \mathrm{aC}$ & $1,25 \mathrm{bB}$ \\
\hline $1 / 2 \mathrm{E}+1 / 2 \mathrm{~V}$ & $12,5 \mathrm{aA}$ & $8,5 \mathrm{aB}$ & $11,4 \mathrm{aA}$ & $1,53 \mathrm{bA}$ & $1,04 \mathrm{bC}$ & $1,11 \mathrm{cB}$ \\
\hline $1 / 2 \mathrm{E}+1 / 2 \mathrm{R}$ & $12,0 \mathrm{aA}$ & $7,4 \mathrm{aB}$ & $12,2 \mathrm{aA}$ & $1,74 \mathrm{aA}$ & $1,17 \mathrm{aC}$ & $1,45 \mathrm{aB}$ \\
\hline $1 / 3 \mathrm{E}+1 / 3 \mathrm{H}+1 / 3 \mathrm{~V}$ & $11,0 \mathrm{bA}$ & $7,8 \mathrm{aB}$ & 10,6 aA & $1,50 \mathrm{bA}$ & $1,10 \mathrm{bC}$ & $1,30 \mathrm{bB}$ \\
\hline $1 / 3 \mathrm{E}+1 / 3 \mathrm{H}+1 / 3 \mathrm{R}$ & $10,1 \mathrm{bA}$ & $4,7 \mathrm{bC}$ & $6,4 \mathrm{bB}$ & $1,37 \mathrm{cA}$ & $1,09 \mathrm{bB}$ & $1,31 \mathrm{bA}$ \\
\hline \multirow[t]{2}{*}{$1 / 4 \mathrm{E}+1 / 4 \mathrm{H}+1 / 4 \mathrm{~V}+1 / 4 \mathrm{R}$} & $10,5 \mathrm{bA}$ & $8,5 \mathrm{aB}$ & $10,8 \mathrm{aA}$ & $1,42 \mathrm{cA}$ & $1,07 \mathrm{bC}$ & $1,20 \mathrm{bB}$ \\
\hline & \multicolumn{3}{|c|}{ Massa seca do sistema radicular (g) } & \multicolumn{3}{|c|}{ Massa seca da parte aérea (g) } \\
\hline $1 / 2 \mathrm{E}+1 / 2 \mathrm{H}$ & $0,020 \mathrm{~b}$ & $0,013 \mathrm{a}$ & $0,012 \mathrm{~b}$ & $0,0928 \mathrm{~b}$ & $0,0350 \mathrm{~b}$ & $0,0375 \mathrm{c}$ \\
\hline $1 / 2 \mathrm{E}+1 / 2 \mathrm{~V}$ & $0,024 \mathrm{a}$ & $0,010 \mathrm{c}$ & $0,009 \mathrm{c}$ & $0,0999 \mathrm{~b}$ & $0,0293 \mathrm{c}$ & $0,0239 \mathrm{~d}$ \\
\hline $1 / 2 \mathrm{E}+1 / 2 \mathrm{R}$ & $0,025 \mathrm{a}$ & $0,013 \mathrm{a}$ & $0,016 \mathrm{a}$ & 0,1339 a & $0,0409 \mathrm{a}$ & $0,0683 \mathrm{a}$ \\
\hline $1 / 3 \mathrm{E}+1 / 3 \mathrm{H}+1 / 3 \mathrm{~V}$ & $0,023 \mathrm{a}$ & $0,011 \mathrm{~b}$ & $0,012 \mathrm{~b}$ & $0,0948 \mathrm{~b}$ & $0,0365 \mathrm{~b}$ & $0,0527 \mathrm{~b}$ \\
\hline $1 / 3 \mathrm{E}+1 / 3 \mathrm{H}+1 / 3 \mathrm{R}$ & $0,018 \mathrm{~b}$ & $0,013 \mathrm{a}$ & $0,012 \mathrm{~b}$ & $0,0703 \mathrm{c}$ & $0,0375 \mathrm{~b}$ & $0,0470 \mathrm{~b}$ \\
\hline \multirow[t]{2}{*}{$1 / 4 \mathrm{E}+1 / 4 \mathrm{H}+1 / 4 \mathrm{~V}+1 / 4 \mathrm{R}$} & $0,020 \mathrm{~b}$ & $0,010 \mathrm{c}$ & $0,009 \mathrm{c}$ & $0,0800 \mathrm{c}$ & $0,0314 \mathrm{c}$ & $0,0346 \mathrm{c}$ \\
\hline & \multicolumn{3}{|c|}{ Índice de Qualidade de Dickson } & \multicolumn{3}{|c|}{ Produção (g) } \\
\hline $1 / 2 \mathrm{E}+1 / 2 \mathrm{H}$ & $0,012 \mathrm{~b}$ & $0,007 \mathrm{a}$ & $0,007 \mathrm{~b}$ & - & - & - \\
\hline $1 / 2 E+1 / 2 V$ & $0,014 \mathrm{a}$ & $0,006 \mathrm{c}$ & $0,006 \mathrm{c}$ & $101,15 \mathrm{aA}$ & $34,52 \mathrm{bC}$ & $73,05 \mathrm{bB}$ \\
\hline $1 / 2 E+1 / 2 R$ & $0,015 \mathrm{a}$ & $0,008 \mathrm{a}$ & $0,010 \mathrm{a}$ & $100,23 \mathrm{aA}$ & $39,06 \mathrm{bB}$ & $98,04 \mathrm{aA}$ \\
\hline $1 / 3 \mathrm{E}+1 / 3 \mathrm{H}+1 / 3 \mathrm{~V}$ & $0,014 \mathrm{a}$ & $0,007 \mathrm{~b}$ & $0,007 \mathrm{~b}$ & $72,46 \mathrm{cA}$ & $45,69 \mathrm{bB}$ & 78,73 bA \\
\hline $1 / 3 \mathrm{E}+1 / 3 \mathrm{H}+1 / 3 \mathrm{R}$ & $0,011 \mathrm{~b}$ & $0,008 \mathrm{a}$ & $0,008 \mathrm{~b}$ & $84,70 \mathrm{bA}$ & $54,30 \mathrm{aB}$ & $69,30 \mathrm{bB}$ \\
\hline $1 / 4 \mathrm{E}+1 / 4 \mathrm{H}+1 / 4 \mathrm{~V}+1 / 4 \mathrm{R}$ & $0,012 \mathrm{~b}$ & $0,006 \mathrm{c}$ & $0,006 \mathrm{c}$ & $57,40 \mathrm{cB}$ & $55,00 \mathrm{aB}$ & $79,00 \mathrm{bA}$ \\
\hline
\end{tabular}

(Banzatto \& Kronka, 2013). Para todas as variáveis houve interação entre os ambientes de cultivo e substratos.

Para a cultivar Tupã, nas análises individuais (substratos) dos três ambientes de cultivo (experimentos), observa-se para as variáveis AP, MSPA e MST da fase de produção das mudas em bandejas que a RQMR foi maior que 7 , não permitindo a comparação dos ambientes de cultivo destas variáveis pela análise conjunta (Banzatto \& Kronka, 2013). Para as demais variáveis, a RQMR foi menor que 7, permitindo a comparação dos ambientes. Para todas as variáveis houve interação entre os ambientes de cultivo e substratos.

Para a cultivar Boyra, nas análises individuais (substratos) dos três ambientes de cultivo (experimentos), verifica-se na fase de produção das mudas em bandejas, que as variáveis MSPA, MSSR, MST e IQD apresentaram RQMR maior que 7 , não permitindo a comparação dos ambientes de cultivo destas variáveis pela análise conjunta (Banzatto \& Kronka, 2013). Para as demais variáveis, a RQMR foi menor que 7 , permitindo a comparação
Tabela 1. Continuação

\begin{tabular}{|c|c|c|c|}
\hline \multirow{2}{*}{ Substratos** } & \multicolumn{3}{|c|}{ Altura da muda (cm) } \\
\hline & Estufa & Sombrite ${ }^{\circledR}$ & Aluminet ${ }^{\circledR}$ \\
\hline $1 / 2 \mathrm{E}+1 / 2 \mathrm{H}$ & $7,06 \mathrm{~b}$ & $4,23 \mathrm{a}$ & $4,44 \mathrm{c}$ \\
\hline $1 / 2 E+1 / 2 V$ & $7,30 \mathrm{~b}$ & $3,98 \mathrm{~b}$ & $3,68 \mathrm{~d}$ \\
\hline $1 / 2 \mathrm{E}+1 / 2 \mathrm{R}$ & $9,68 \mathrm{a}$ & $4,41 \mathrm{a}$ & $5,91 \mathrm{a}$ \\
\hline $1 / 3 \mathrm{E}+1 / 3 \mathrm{H}+1 / 3 \mathrm{~V}$ & $6,84 b$ & $4,26 \mathrm{a}$ & $5,17 \mathrm{~b}$ \\
\hline $1 / 3 \mathrm{E}+1 / 3 \mathrm{H}+1 / 3 \mathrm{R}$ & $6,01 \mathrm{c}$ & $4,11 \mathrm{~b}$ & $4,62 \mathrm{c}$ \\
\hline \multirow[t]{2}{*}{$1 / 4 \mathrm{E}+1 / 4 \mathrm{H}+1 / 4 \mathrm{~V}+1 / 4 \mathrm{R}$} & $6,28 \mathrm{c}$ & $4,19 \mathrm{a}$ & $4,41 \mathrm{c}$ \\
\hline & \multicolumn{3}{|c|}{ Massa seca total (g) } \\
\hline $1 / 2 \mathrm{E}+1 / 2 \mathrm{H}$ & $0,1122 \mathrm{~b}$ & $0,0478 \mathrm{~b}$ & $0,0492 \mathrm{c}$ \\
\hline $1 / 2 \mathrm{E}+1 / 2 \mathrm{~V}$ & $0,1238 \mathrm{~b}$ & $0,0396 \mathrm{c}$ & $0,0330 \mathrm{~d}$ \\
\hline $1 / 2 \mathrm{E}+1 / 2 \mathrm{R}$ & $0,1593 \mathrm{a}$ & $0,0542 \mathrm{a}$ & $0,0846 \mathrm{a}$ \\
\hline $1 / 3 \mathrm{E}+1 / 3 \mathrm{H}+1 / 3 \mathrm{~V}$ & $0,1178 \mathrm{~b}$ & $0,0479 \mathrm{~b}$ & $0,0641 \mathrm{~b}$ \\
\hline $1 / 3 \mathrm{E}+1 / 3 \mathrm{H}+1 / 3 \mathrm{R}$ & $0,0881 \mathrm{c}$ & $0,0503 \mathrm{~b}$ & $0,0594 \mathrm{~b}$ \\
\hline \multirow[t]{2}{*}{$1 / 4 \mathrm{E}+1 / 4 \mathrm{H}+1 / 4 \mathrm{~V}+1 / 4 \mathrm{R}$} & $0,1001 \mathrm{c}$ & $0,0411 \mathrm{c}$ & $0,0440 \mathrm{c}$ \\
\hline & \multicolumn{3}{|c|}{ Frutos $\left(n^{0}\right)$} \\
\hline $1 / 2 \mathrm{E}+1 / 2 \mathrm{H}$ & - & - & - \\
\hline $1 / 2 E+1 / 2 V$ & $94,63 \mathrm{aA}$ & $44,13 \mathrm{aC}$ & $79,00 \mathrm{bB}$ \\
\hline $1 / 2 E+1 / 2 R$ & $87,88 \mathrm{aB}$ & $43,13 \mathrm{aC}$ & $102,63 \mathrm{aA}$ \\
\hline $1 / 3 \mathrm{E}+1 / 3 \mathrm{H}+1 / 3 \mathrm{~V}$ & $71,13 \mathrm{bA}$ & $45,25 \mathrm{aB}$ & $77,75 \mathrm{bA}$ \\
\hline $1 / 3 \mathrm{E}+1 / 3 \mathrm{H}+1 / 3 \mathrm{R}$ & $76,50 \mathrm{bA}$ & $55,40 \mathrm{aB}$ & $72,40 \mathrm{bA}$ \\
\hline $1 / 4 \mathrm{E}+1 / 4 \mathrm{H}+1 / 4 \mathrm{~V}+1 / 4 \mathrm{R}$ & $57,10 \mathrm{cB}$ & $54,40 \mathrm{aB}$ & $79,90 \mathrm{bA}$ \\
\hline
\end{tabular}

*Letras iguais minúsculas nas colunas e maiúsculas nas linhas, para cada parâmetro, não diferem entre si pelo Teste de Scott-Knott a 5\% de probabilidade (for each parameter, the same lowercase letters in columns and uppercase letters in rows do not differ by Scott-Knott, $5 \%) ; * * \mathrm{E}=$ esterco bovino (cattle manure); $\mathrm{H}=$ húmus de minhoca (earthworm humus); $\mathrm{R}=$ ramas de mandioca (cassava stems); $\mathrm{V}=$ vermiculita (vermiculite). 
Tabela 2. Ambientes e substratos na fase de produção das mudas em bandejas e de produção de frutos em vasos de pimenteira em bandejas, cultivar Pirâmide (environments and substrates during seedlings and fruit production phase for pepper production, cv. Pirâmide). Aquidauana, UEMS, 2012.

\begin{tabular}{|c|c|c|c|c|c|c|}
\hline \multirow{2}{*}{ Substratos** } & \multicolumn{3}{|c|}{ Índice de velocidade de emergência } & \multicolumn{3}{|c|}{ Diâmetro do colo (mm) } \\
\hline & Estufa & Sombrite ${ }^{\circledR}$ & Aluminet ${ }^{\circledR}$ & Estufa & Sombrite ${ }^{\circledR}$ & Aluminet ${ }^{\circledR}$ \\
\hline $1 / 2 \mathrm{E}+1 / 2 \mathrm{H}$ & $6,26 \mathrm{cA}^{*}$ & $3,20 \mathrm{cB}$ & $5,55 \mathrm{bA}$ & $1,36 \mathrm{dA}$ & $1,36 \mathrm{dA}$ & $1,36 \mathrm{dA}$ \\
\hline $1 / 2 \mathrm{E}+1 / 2 \mathrm{~V}$ & $10,83 \mathrm{aA}$ & $8,19 \mathrm{aB}$ & $8,08 \mathrm{aB}$ & $1,42 \mathrm{cA}$ & $1,42 \mathrm{cA}$ & $1,42 \mathrm{cA}$ \\
\hline $1 / 2 \mathrm{E}+1 / 2 \mathrm{R}$ & $6,53 \mathrm{cA}$ & $5,21 \mathrm{bB}$ & $7,61 \mathrm{aA}$ & $1,61 \mathrm{bA}$ & $1,61 \mathrm{bA}$ & $1,61 \mathrm{bA}$ \\
\hline $1 / 3 \mathrm{E}+1 / 3 \mathrm{H}+1 / 3 \mathrm{~V}$ & $7,59 \mathrm{cA}$ & 7,64 aA & $8,44 \mathrm{aA}$ & $1,60 \mathrm{bA}$ & $1,60 \mathrm{bA}$ & $1,60 \mathrm{bA}$ \\
\hline $1 / 3 \mathrm{E}+1 / 3 \mathrm{H}+1 / 3 \mathrm{R}$ & $10,37 \mathrm{aA}$ & $6,74 \mathrm{aB}$ & $7,01 \mathrm{aB}$ & $1,69 \mathrm{aA}$ & $1,69 \mathrm{aA}$ & $1,69 \mathrm{aA}$ \\
\hline \multirow[t]{2}{*}{$1 / 4 \mathrm{E}+1 / 4 \mathrm{H}+1 / 4 \mathrm{~V}+1 / 4 \mathrm{R}$} & $8,73 \mathrm{bA}$ & $7,86 \mathrm{aA}$ & $5,54 \mathrm{bB}$ & $1,47 \mathrm{cA}$ & $1,47 \mathrm{cA}$ & $1,47 \mathrm{cA}$ \\
\hline & \multicolumn{3}{|c|}{ Massa seca do sistema radicular (g) } & \multicolumn{3}{|c|}{ Massa seca da parte aérea (g) } \\
\hline $1 / 2 \mathrm{E}+1 / 2 \mathrm{H}$ & $0,0154 \mathrm{cA}$ & $0,0139 \mathrm{aA}$ & $0,0126 \mathrm{aA}$ & $0,0609 \mathrm{cA}$ & $0,0407 \mathrm{bB}$ & $0,0485 \mathrm{bB}$ \\
\hline $1 / 2 \mathrm{E}+1 / 2 \mathrm{~V}$ & $0,0168 \mathrm{cA}$ & $0,0083 \mathrm{cC}$ & $0,0106 \mathrm{bB}$ & $0,0696 \mathrm{cA}$ & $0,0351 \mathrm{bB}$ & $0,0346 \mathrm{cB}$ \\
\hline $1 / 2 \mathrm{E}+1 / 2 \mathrm{R}$ & $0,0199 \mathrm{bA}$ & $0,0110 \mathrm{bB}$ & $0,0123 \mathrm{aB}$ & $0,0989 \mathrm{aA}$ & $0,0490 \mathrm{aC}$ & $0,0638 \mathrm{aB}$ \\
\hline $1 / 3 \mathrm{E}+1 / 3 \mathrm{H}+1 / 3 \mathrm{~V}$ & $0,0203 \mathrm{bA}$ & $0,0124 \mathrm{aB}$ & $0,0143 \mathrm{aB}$ & $0,0992 \mathrm{aA}$ & $0,0449 \mathrm{aC}$ & $0,0616 \mathrm{aB}$ \\
\hline $1 / 3 \mathrm{E}+1 / 3 \mathrm{H}+1 / 3 \mathrm{R}$ & $0,0223 \mathrm{aA}$ & $0,0125 \mathrm{aB}$ & $0,0119 \mathrm{aB}$ & $0,1076 \mathrm{aA}$ & $0,0520 \mathrm{aC}$ & $0,0656 \mathrm{aB}$ \\
\hline \multirow[t]{2}{*}{$1 / 4 \mathrm{E}+1 / 4 \mathrm{H}+1 / 4 \mathrm{~V}+1 / 4 \mathrm{R}$} & $0,0166 \mathrm{cA}$ & $0,0107 \mathrm{bB}$ & $0,0091 \mathrm{bB}$ & $0,0796 \mathrm{bA}$ & $0,0411 \mathrm{bB}$ & $0,0394 \mathrm{cB}$ \\
\hline & \multicolumn{3}{|c|}{ Índice de Qualidade de Dickson } & \multicolumn{3}{|c|}{ Produção (g) } \\
\hline $1 / 2 \mathrm{E}+1 / 2 \mathrm{H}$ & $0,0115 \mathrm{bA}$ & $0,0096 \mathrm{aB}$ & $0,0101 \mathrm{aB}$ & - & - & - \\
\hline $1 / 2 \mathrm{E}+1 / 2 \mathrm{~V}$ & $0,0128 \mathrm{bA}$ & $0,0064 \mathrm{bC}$ & $0,0083 \mathrm{bB}$ & $69,10 \mathrm{bC}$ & $124,47 \mathrm{aA}$ & 99,58 bB \\
\hline $1 / 2 \mathrm{E}+1 / 2 \mathrm{R}$ & $0,0153 \mathrm{aA}$ & $0,0086 \mathrm{aC}$ & $0,0101 \mathrm{aB}$ & 82,48 bB & $128,36 \mathrm{aA}$ & $136,08 \mathrm{aA}$ \\
\hline $1 / 3 \mathrm{E}+1 / 3 \mathrm{H}+1 / 3 \mathrm{~V}$ & $0,0151 \mathrm{aA}$ & $0,0094 \mathrm{aC}$ & $0,0114 \mathrm{aB}$ & $119,82 \mathrm{aA}$ & $87,30 \mathrm{bB}$ & $113,65 \mathrm{bA}$ \\
\hline $1 / 3 \mathrm{E}+1 / 3 \mathrm{H}+1 / 3 \mathrm{R}$ & $0,0166 \mathrm{aA}$ & $0,0096 \mathrm{aB}$ & $0,0098 \mathrm{aB}$ & $109,60 \mathrm{aA}$ & $91,90 \mathrm{bA}$ & 89,10 bA \\
\hline $1 / 4 \mathrm{E}+1 / 4 \mathrm{H}+1 / 4 \mathrm{~V}+1 / 4 \mathrm{R}$ & $0,0125 \mathrm{bA}$ & $0,0078 \mathrm{bB}$ & $0,0072 \mathrm{bB}$ & $132,30 \mathrm{aA}$ & $88,30 \mathrm{bB}$ & $103,10 \mathrm{bB}$ \\
\hline
\end{tabular}

dos ambientes. Para as variáveis que permitiram a análise conjunta, houve interação entre esses dois fatores estudados (ambientes e substratos).

\section{Cultivar ornamental Etna}

Os ambientes de cultivo utilizados foram adequados, principalmente a estufa, quando combinado ao uso do substrato contendo $50 \%$ de esterco e $50 \%$ de ramas de mandioca triturada $(1 / 2 E+1 / 2 R)$, formando, assim, mudas de melhor qualidade em menor tempo, ou seja, com valores maiores do IVE, DC, MSSR, IQD, superior às demais, (Tabela 1). Isso corroborou com os resultados obtidos por Costa et al. (2015a), que verificaram melhores mudas do tomate cereja no substrato contendo $50 \%$ de rama de mandioca $+50 \%$ de esterco bovino, assim como no substrato contendo $25 \%$ de rama de mandioca + $25 \%$ de Vida Verde ${ }^{\circledR}+25 \%$ de esterco aviário $+25 \%$ de esterco bovino.

O emprego de matéria orgânica no substrato de cultivo promove maior disponibilidade de nutrientes às plântulas e melhora as condições físicas do substrato (Rodrigues et al., 2010),
Tabela 2. Continuação

\begin{tabular}{|c|c|c|c|}
\hline \multirow{2}{*}{ Substratos** } & \multicolumn{3}{|c|}{ Altura da muda (cm) } \\
\hline & Estufa & Sombrite $®$ & Aluminet ${ }^{\circledR}$ \\
\hline $1 / 2 \mathrm{E}+1 / 2 \mathrm{H}$ & $3,65 \mathrm{dA}$ & $3,65 \mathrm{dA}$ & $3,65 \mathrm{dA}$ \\
\hline $1 / 2 E+1 / 2 V$ & $3,64 \mathrm{dA}$ & $3,64 \mathrm{dA}$ & $3,64 \mathrm{dA}$ \\
\hline $1 / 2 E+1 / 2 R$ & $4,47 \mathrm{cA}$ & $4,47 \mathrm{cA}$ & $4,47 \mathrm{cA}$ \\
\hline $1 / 3 \mathrm{E}+1 / 3 \mathrm{H}+1 / 3 \mathrm{~V}$ & $4,77 \mathrm{bA}$ & $4,77 \mathrm{bA}$ & $4,77 \mathrm{bA}$ \\
\hline $1 / 3 \mathrm{E}+1 / 3 \mathrm{H}+1 / 3 \mathrm{R}$ & $5,07 \mathrm{aA}$ & $5,07 \mathrm{aA}$ & $5,07 \mathrm{aA}$ \\
\hline \multirow[t]{2}{*}{$1 / 4 \mathrm{E}+1 / 4 \mathrm{H}+1 / 4 \mathrm{~V}+1 / 4 \mathrm{R}$} & $4,27 \mathrm{cA}$ & $4,27 \mathrm{cA}$ & $4,27 \mathrm{cA}$ \\
\hline & \multicolumn{3}{|c|}{ Massa seca total (g) } \\
\hline $1 / 2 \mathrm{E}+1 / 2 \mathrm{H}$ & $0,0763 \mathrm{dA}$ & $0,0546 \mathrm{aB}$ & $0,0611 \mathrm{bB}$ \\
\hline $1 / 2 \mathrm{E}+1 / 2 \mathrm{~V}$ & $0,0863 \mathrm{cA}$ & $0,0434 \mathrm{bB}$ & $0,0452 \mathrm{cB}$ \\
\hline $1 / 2 E+1 / 2 R$ & $0,1187 \mathrm{bA}$ & $0,0600 \mathrm{aC}$ & $0,0761 \mathrm{aB}$ \\
\hline $1 / 3 \mathrm{E}+1 / 3 \mathrm{H}+1 / 3 \mathrm{~V}$ & $0,1195 \mathrm{bA}$ & $0,0574 \mathrm{aC}$ & $0,0759 \mathrm{aB}$ \\
\hline $1 / 3 \mathrm{E}+1 / 3 \mathrm{H}+1 / 3 \mathrm{R}$ & $0,1300 \mathrm{aA}$ & $0,0646 \mathrm{aC}$ & $0,0775 \mathrm{aB}$ \\
\hline \multirow[t]{2}{*}{$1 / 4 \mathrm{E}+1 / 4 \mathrm{H}+1 / 4 \mathrm{~V}+1 / 4 \mathrm{R}$} & $0,0962 \mathrm{cA}$ & $0,0518 \mathrm{bB}$ & $0,0485 \mathrm{cB}$ \\
\hline & \multicolumn{3}{|c|}{ Frutos $\left(n^{0}\right)$} \\
\hline $1 / 2 \mathrm{E}+1 / 2 \mathrm{H}$ & - & - & - \\
\hline $1 / 2 \mathrm{E}+1 / 2 \mathrm{~V}$ & $42,25 \mathrm{cC}$ & 70,13 aA & $58,63 \mathrm{bB}$ \\
\hline $1 / 2 E+1 / 2 R$ & $50,75 \mathrm{cB}$ & 68,75 aA & $70,25 \mathrm{aA}$ \\
\hline $1 / 3 \mathrm{E}+1 / 3 \mathrm{H}+1 / 3 \mathrm{~V}$ & $74,38 \mathrm{aA}$ & $47,38 \mathrm{bC}$ & $57,25 \mathrm{bB}$ \\
\hline $1 / 3 \mathrm{E}+1 / 3 \mathrm{H}+1 / 3 \mathrm{R}$ & $66,60 \mathrm{bA}$ & $48,50 \mathrm{bB}$ & $48,80 \mathrm{bB}$ \\
\hline $1 / 4 \mathrm{E}+1 / 4 \mathrm{H}+1 / 4 \mathrm{~V}+1 / 4 \mathrm{R}$ & $77,90 \mathrm{aA}$ & $43,60 \mathrm{bB}$ & $52,30 \mathrm{bB}$ \\
\hline
\end{tabular}

*Letras iguais minúsculas nas colunas e maiúsculas nas linhas, para cada parâmetro, não diferem entre si pelo Teste de Scott-Knott a 5\% de probabilidade (for each parameter, the same lowercase letters in columns and uppercase letters in rows do not differ by Scott-Knott, $5 \%$ ); $* * \mathrm{E}=$ esterco bovino (cattle manure); $\mathrm{H}=$ húmus de minhoca (earthworm humus); $\mathrm{R}=$ ramas de mandioca (cassava stems); $\mathrm{V}=$ vermiculita (vermiculite). 
Tabela 3. Ambientes e substratos na fase de produção das mudas em bandejas e de produção de frutos em vasos de pimenteira em bandejas, cultivar Tupã (environments and substrates during seedlings and fruit production phase for pepper production, cv. Tupã). Aquidauana, UEMS, 2012.

\begin{tabular}{|c|c|c|c|c|c|c|}
\hline \multirow{2}{*}{ Substratos $* *$} & \multicolumn{3}{|c|}{ Índice de velocidade de emergência } & \multicolumn{3}{|c|}{ Diâmetro do colo (mm) } \\
\hline & Estufa & 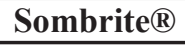 & 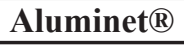 & Estufa & 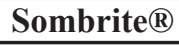 & Aluminet $\mathbb{R}$ \\
\hline $1 / 2 \mathrm{E}+1 / 2 \mathrm{H}$ & $10,29 \mathrm{aA}^{*}$ & $3,98 \mathrm{bB}$ & $2,83 \mathrm{cB}$ & $1,55 \mathrm{aA}$ & $1,24 \mathrm{aB}$ & $1,22 \mathrm{bB}$ \\
\hline $1 / 2 \mathrm{E}+1 / 2 \mathrm{~V}$ & $10,82 \mathrm{aA}$ & $6,66 \mathrm{aB}$ & $9,88 \mathrm{aA}$ & $1,36 \mathrm{bA}$ & $1,12 \mathrm{bB}$ & $1,38 \mathrm{aA}$ \\
\hline $1 / 2 E+1 / 2 R$ & $11,10 \mathrm{aA}$ & $7,56 \mathrm{aB}$ & $7,15 \mathrm{bB}$ & $1,62 \mathrm{aA}$ & $1,25 \mathrm{aC}$ & $1,43 \mathrm{aB}$ \\
\hline $1 / 3 \mathrm{E}+1 / 3 \mathrm{H}+1 / 3 \mathrm{~V}$ & $11,28 \mathrm{aA}$ & $4,89 \mathrm{bC}$ & $9,24 \mathrm{aB}$ & $1,56 \mathrm{aA}$ & $1,21 \mathrm{aC}$ & $1,39 \mathrm{aB}$ \\
\hline $1 / 3 \mathrm{E}+1 / 3 \mathrm{H}+1 / 3 \mathrm{R}$ & $8,50 \mathrm{bA}$ & $3,57 \mathrm{bB}$ & $8,81 \mathrm{aA}$ & $1,56 \mathrm{aA}$ & $1,19 \mathrm{aC}$ & $1,30 \mathrm{aB}$ \\
\hline \multirow[t]{2}{*}{$1 / 4 \mathrm{E}+1 / 4 \mathrm{H}+1 / 4 \mathrm{~V}+1 / 4 \mathrm{R}$} & $7,29 \mathrm{bA}$ & $7,53 \mathrm{aA}$ & $7,11 \mathrm{bA}$ & $1,40 \mathrm{bA}$ & $1,21 \mathrm{aC}$ & $1,29 \mathrm{aB}$ \\
\hline & \multicolumn{3}{|c|}{ Massa seca do sistema radicular (g) } & \multicolumn{3}{|c|}{ Massa seca da parte aérea (g) } \\
\hline $1 / 2 \mathrm{E}+1 / 2 \mathrm{H}$ & $0,0195 \mathrm{aA}$ & $0,0124 \mathrm{aB}$ & $0,0082 \mathrm{bC}$ & $0,0845 \mathrm{a}$ & $0,0344 \mathrm{c}$ & $0,0271 \mathrm{~b}$ \\
\hline $1 / 2 \mathrm{E}+1 / 2 \mathrm{~V}$ & $0,0164 \mathrm{bA}$ & $0,0093 \mathrm{bB}$ & $0,0111 \mathrm{aB}$ & $0,0620 \mathrm{~b}$ & $0,0256 \mathrm{~b}$ & $0,0358 \mathrm{a}$ \\
\hline $1 / 2 \mathrm{E}+1 / 2 \mathrm{R}$ & $0,0183 \mathrm{aA}$ & $0,0115 \mathrm{aB}$ & $0,0119 \mathrm{aB}$ & $0,0914 \mathrm{a}$ & $0,0349 \mathrm{~b}$ & $0,0400 \mathrm{a}$ \\
\hline $1 / 3 \mathrm{E}+1 / 3 \mathrm{H}+1 / 3 \mathrm{~V}$ & $0,0157 \mathrm{bA}$ & $0,0115 \mathrm{aB}$ & $0,0103 \mathrm{aB}$ & $0,0889 \mathrm{a}$ & $0,0385 \mathrm{a}$ & $0,0438 \mathrm{a}$ \\
\hline $1 / 3 \mathrm{E}+1 / 3 \mathrm{H}+1 / 3 \mathrm{R}$ & $0,0167 \mathrm{bA}$ & $0,0092 \mathrm{bB}$ & $0,0114 \mathrm{aB}$ & $0,0869 \mathrm{a}$ & $0,0320 \mathrm{~b}$ & 0,0383 a \\
\hline \multirow[t]{2}{*}{$1 / 4 \mathrm{E}+1 / 4 \mathrm{H}+1 / 4 \mathrm{~V}+1 / 4 \mathrm{R}$} & $0,0109 \mathrm{cA}$ & $0,0102 \mathrm{bA}$ & $0,0079 \mathrm{bB}$ & $0,0555 \mathrm{~b}$ & $0,0343 \mathrm{~b}$ & $0,0349 \mathrm{a}$ \\
\hline & \multicolumn{3}{|c|}{ Índice de Qualidade de Dickson } & \multicolumn{3}{|c|}{ Produção (g) } \\
\hline $1 / 2 \mathrm{E}+1 / 2 \mathrm{H}$ & $0,0129 \mathrm{aA}$ & $0,0086 \mathrm{aB}$ & $0,0064 \mathrm{bC}$ & - & - & - \\
\hline $1 / 2 \mathrm{E}+1 / 2 \mathrm{~V}$ & $0,0110 \mathrm{bA}$ & $0,0065 \mathrm{bC}$ & $0,0084 \mathrm{aB}$ & $94,65 \mathrm{aA}$ & $79,44 \mathrm{aA}$ & $62,16 \mathrm{bB}$ \\
\hline $1 / 2 \mathrm{E}+1 / 2 \mathrm{R}$ & $0,0125 \mathrm{aA}$ & $0,0080 \mathrm{aB}$ & $0,0090 \mathrm{aA}$ & $82,83 \mathrm{bB}$ & $68,51 \mathrm{aB}$ & $112,73 \mathrm{aA}$ \\
\hline $1 / 3 \mathrm{E}+1 / 3 \mathrm{H}+1 / 3 \mathrm{~V}$ & $0,0112 \mathrm{bA}$ & $0,0084 \mathrm{aB}$ & $0,0078 \mathrm{aB}$ & $72,39 \mathrm{bA}$ & $65,47 \mathrm{aA}$ & $70,80 \mathrm{bA}$ \\
\hline $1 / 3 \mathrm{E}+1 / 3 \mathrm{H}+1 / 3 \mathrm{R}$ & $0,0117 \mathrm{bA}$ & $0,0067 \mathrm{bC}$ & $0,0082 \mathrm{aB}$ & $104,60 \mathrm{aA}$ & $57,30 \mathrm{bB}$ & $45,40 \mathrm{cB}$ \\
\hline $1 / 4 \mathrm{E}+1 / 4 \mathrm{H}+1 / 4 \mathrm{~V}+1 / 4 \mathrm{R}$ & $0,0084 \mathrm{bA}$ & $0,0071 \mathrm{bB}$ & $0,0060 \mathrm{bB}$ & $93,30 \mathrm{aA}$ & $53,40 \mathrm{bB}$ & $52,10 \mathrm{cB}$ \\
\hline
\end{tabular}

resultando, portanto, em mudas melhor desenvolvidas. No presente trabalho, essa mistura contendo $50 \%$ de esterco $+50 \%$ de ramas trituradas de mandioca se assemelha à formação de mudas de melhor qualidade de pimentão em substrato contendo $50 \%$ esterco bovino $+50 \%$ Plantmax $^{\circledR}$ (Costa et al., 2013a).

O substrato contendo $50 \%$ de esterco bovino e $50 \%$ de vermiculita não propiciou mudas de elevada qualidade da pimenteira ornamental comparado com os substratos utilizados, corroborando com os resultados obtidos por Costa et al. (2015a) para o tomate cereja. Costa et al. (2015b), estudando distintas proporções de vermiculita e esterco bovino para produção de mudas de pimenteira ornamental, cultivar Etna, na região de Cassilândia-MS, constataram que altas proporções de vermiculita no substrato de cultivo aumentam a velocidade e porcentagem de emergência, não influindo porem sobre os aspectos de qualidade de mudas.

Para este estudo as ramas de mandioca trituradas foram compostadas por 72 dias e, no trabalho de Costa et
Tabela 3. Continuação

\begin{tabular}{lccc}
\hline \multirow{2}{*}{ Substratos** } & \multicolumn{3}{c}{ Altura da muda (cm) } \\
\cline { 2 - 4 } & Estufa & Sombrite ${ }^{\circ}$ & Aluminet ${ }^{\circledR}$ \\
\hline $1 / 2 \mathrm{E}+1 / 2 \mathrm{H}$ & $5,78 \mathrm{a}$ & $3,27 \mathrm{~b}$ & $2,61 \mathrm{~d}$ \\
$1 / 2 \mathrm{E}+1 / 2 \mathrm{~V}$ & $4,50 \mathrm{~b}$ & $2,94 \mathrm{c}$ & $3,19 \mathrm{c}$ \\
$1 / 2 \mathrm{E}+1 / 2 \mathrm{R}$ & $6,14 \mathrm{a}$ & $3,45 \mathrm{a}$ & $3,39 \mathrm{~b}$ \\
$1 / 3 \mathrm{E}+1 / 3 \mathrm{H}+1 / 3 \mathrm{~V}$ & $5,69 \mathrm{a}$ & $3,15 \mathrm{~b}$ & $3,73 \mathrm{a}$ \\
$1 / 3 \mathrm{E}+1 / 3 \mathrm{H}+1 / 3 \mathrm{R}$ & $5,57 \mathrm{a}$ & $3,12 \mathrm{~b}$ & $3,49 \mathrm{~b}$ \\
$1 / 4 \mathrm{E}+1 / 4 \mathrm{H}+1 / 4 \mathrm{~V}+1 / 4 \mathrm{R}$ & $3,98 \mathrm{~b}$ & $3,57 \mathrm{a}$ & $3,45 \mathrm{~b}$ \\
\hline & & Massa seca total $(\mathbf{g})$ \\
\hline $1 / 2 \mathrm{E}+1 / 2 \mathrm{H}$ & $0,1041 \mathrm{a}$ & $0,0468 \mathrm{a}$ & $0,0353 \mathrm{c}$ \\
$1 / 2 \mathrm{E}+1 / 2 \mathrm{~V}$ & $0,0783 \mathrm{~b}$ & $0,0349 \mathrm{c}$ & $0,0468 \mathrm{a}$ \\
$1 / 2 \mathrm{E}+1 / 2 \mathrm{R}$ & $0,1097 \mathrm{a}$ & $0,0464 \mathrm{a}$ & $0,0519 \mathrm{a}$ \\
$1 / 3 \mathrm{E}+1 / 3 \mathrm{H}+1 / 3 \mathrm{~V}$ & $0,1046 \mathrm{a}$ & $0,0500 \mathrm{a}$ & $0,0541 \mathrm{a}$ \\
$1 / 3 \mathrm{E}+1 / 3 \mathrm{H}+1 / 3 \mathrm{R}$ & $0,1036 \mathrm{a}$ & $0,0413 \mathrm{~b}$ & $0,0497 \mathrm{a}$ \\
$1 / 4 \mathrm{E}+1 / 4 \mathrm{H}+1 / 4 \mathrm{~V}+1 / 4 \mathrm{R}$ & $0,0664 \mathrm{~b}$ & $0,0446 \mathrm{a}$ & $0,0428 \mathrm{~b}$ \\
\hline
\end{tabular}

\begin{tabular}{lccc}
\multicolumn{3}{c}{ Frutos $\left(\mathbf{n}^{\mathbf{0}}\right)$} \\
\hline $1 / 2 \mathrm{E}+1 / 2 \mathrm{H}$ & - & - & - \\
$1 / 2 \mathrm{E}+1 / 2 \mathrm{~V}$ & $82,50 \mathrm{aA}$ & $58,38 \mathrm{aB}$ & $52,38 \mathrm{bB}$ \\
$1 / 2 \mathrm{E}+1 / 2 \mathrm{R}$ & $79,50 \mathrm{aA}$ & $58,25 \mathrm{aB}$ & $90,50 \mathrm{aA}$ \\
$1 / 3 \mathrm{E}+1 / 3 \mathrm{H}+1 / 3 \mathrm{~V}$ & $63,38 \mathrm{bA}$ & $56,25 \mathrm{aA}$ & $59,25 \mathrm{bA}$ \\
$1 / 3 \mathrm{E}+1 / 3 \mathrm{H}+1 / 3 \mathrm{R}$ & $90,50 \mathrm{aA}$ & $50,10 \mathrm{aB}$ & $40,40 \mathrm{cB}$ \\
$1 / 4 \mathrm{E}+1 / 4 \mathrm{H}+1 / 4 \mathrm{~V}+1 / 4 \mathrm{R}$ & $77,00 \mathrm{aA}$ & $46,40 \mathrm{aB}$ & $45,00 \mathrm{cB}$ \\
\hline
\end{tabular}

*Letras iguais minúsculas nas colunas e maiúsculas nas linhas, para cada parâmetro, não diferem entre si pelo Teste de Scott-Knott a $5 \%$ de probabilidade (for each parameter, the same lowercase letters in columns and uppercase letters in rows do not differ by Scott-Knott, $5 \%$ ); $* *=$ esterco bovino (cattle manure); $\mathrm{H}=$ húmus de minhoca (earthworm humus); $\mathrm{R}=$ ramas de mandioca (cassava stems); $\mathrm{V}=$ vermiculita (vermiculite). 
Tabela 4. Ambientes e substratos na fase de produção das mudas em bandejas e de produção de frutos em vasos de pimenteira em bandejas, cultivar Boyra (environments and substrates during seedlings and fruit production phase for pepper production, cv. Boyra). Aquidauana, UEMS, 2012.

\begin{tabular}{|c|c|c|c|c|c|c|}
\hline \multirow{2}{*}{ Substratos** } & \multicolumn{3}{|c|}{ Índice de velocidade de emergência } & \multicolumn{3}{|c|}{ Diâmetro do colo (mm) } \\
\hline & Estufa & Sombrite® & Aluminet ${ }^{\circledR}$ & Estufa & Sombrite® & Aluminet ${ }^{\circledR}$ \\
\hline $1 / 2 \mathrm{E}+1 / 2 \mathrm{H}$ & $11,24 \mathrm{aA}^{*}$ & $4,78 \mathrm{bB}$ & $5,80 \mathrm{cB}$ & $1,48 \mathrm{bA}$ & $1,17 \mathrm{aB}$ & $1,21 \mathrm{bB}$ \\
\hline $1 / 2 \mathrm{E}+1 / 2 \mathrm{~V}$ & $10,33 \mathrm{aA}$ & $10,95 \mathrm{aA}$ & $12,05 \mathrm{aA}$ & $1,23 \mathrm{cA}$ & $1,16 \mathrm{aA}$ & $1,20 \mathrm{bA}$ \\
\hline $1 / 2 E+1 / 2 R$ & $11,19 \mathrm{aA}$ & $8,23 \mathrm{bB}$ & $10,45 \mathrm{bA}$ & $1,62 \mathrm{aA}$ & $1,19 \mathrm{aC}$ & $1,31 \mathrm{aB}$ \\
\hline $1 / 3 \mathrm{E}+1 / 3 \mathrm{H}+1 / 3 \mathrm{~V}$ & $12,41 \mathrm{aA}$ & $9,96 \mathrm{aB}$ & $8,57 \mathrm{bB}$ & $1,57 \mathrm{aA}$ & $1,20 \mathrm{aC}$ & $1,26 \mathrm{aB}$ \\
\hline $1 / 3 \mathrm{E}+1 / 3 \mathrm{H}+1 / 3 \mathrm{R}$ & $7,66 \mathrm{bB}$ & $5,39 \mathrm{bC}$ & $9,96 \mathrm{bA}$ & $1,44 \mathrm{bA}$ & $1,22 \mathrm{aB}$ & $1,27 \mathrm{aB}$ \\
\hline \multirow[t]{2}{*}{$1 / 4 \mathrm{E}+1 / 4 \mathrm{H}+1 / 4 \mathrm{~V}+1 / 4 \mathrm{R}$} & $7,16 \mathrm{bB}$ & $10,44 \mathrm{aA}$ & $10,37 \mathrm{bA}$ & $1,34 \mathrm{bA}$ & $1,13 \mathrm{aC}$ & $1,20 \mathrm{bB}$ \\
\hline & \multicolumn{3}{|c|}{ Massa seca do sistema radicular (g) } & \multicolumn{3}{|c|}{ Massa seca da parte aérea (g) } \\
\hline $1 / 2 \mathrm{E}+1 / 2 \mathrm{H}$ & $0,0177 \mathrm{a}$ & $0,0078 \mathrm{~b}$ & $0,0088 \mathrm{c}$ & $0,0813 \mathrm{a}$ & $0,0403 \mathrm{~b}$ & $0,0394 \mathrm{~b}$ \\
\hline $1 / 2 \mathrm{E}+1 / 2 \mathrm{~V}$ & 0,0129 a & $0,0090 \mathrm{~b}$ & $0,0146 \mathrm{a}$ & $0,0479 \mathrm{~b}$ & $0,0355 \mathrm{~b}$ & $0,0346 \mathrm{c}$ \\
\hline $1 / 2 E+1 / 2 R$ & $0,0201 \mathrm{a}$ & $0,0105 \mathrm{a}$ & $0,0101 \mathrm{c}$ & 0,0918 a & $0,0453 \mathrm{a}$ & $0,0478 \mathrm{a}$ \\
\hline $1 / 3 \mathrm{E}+1 / 3 \mathrm{H}+1 / 3 \mathrm{~V}$ & 0,0185 a & $0,0111 \mathrm{a}$ & $0,0095 \mathrm{c}$ & $0,0913 \mathrm{a}$ & $0,0410 \mathrm{~b}$ & $0,0406 \mathrm{~b}$ \\
\hline $1 / 3 \mathrm{E}+1 / 3 \mathrm{H}+1 / 3 \mathrm{R}$ & $0,0340 \mathrm{a}$ & $0,0124 \mathrm{a}$ & $0,0119 \mathrm{~b}$ & $0,0621 \mathrm{~b}$ & $0,0463 \mathrm{a}$ & $0,0440 \mathrm{a}$ \\
\hline \multirow[t]{2}{*}{$1 / 4 \mathrm{E}+1 / 4 \mathrm{H}+1 / 4 \mathrm{~V}+1 / 4 \mathrm{R}$} & $0,0110 \mathrm{a}$ & $0,0112 \mathrm{a}$ & $0,0080 \mathrm{c}$ & $0,0529 \mathrm{~b}$ & $0,0386 \mathrm{~b}$ & $0,0335 \mathrm{c}$ \\
\hline & \multicolumn{3}{|c|}{ Índice de Qualidade de Dickson } & \multicolumn{3}{|c|}{ Produção (g) } \\
\hline $1 / 2 \mathrm{E}+1 / 2 \mathrm{H}$ & $0,0116 \mathrm{a}$ & $0,0059 \mathrm{c}$ & $0,0066 \mathrm{c}$ & - & - & - \\
\hline $1 / 2 \mathrm{E}+1 / 2 \mathrm{~V}$ & $0,0088 \mathrm{a}$ & $0,0062 \mathrm{c}$ & $0,0095 \mathrm{a}$ & $210,82 \mathrm{bA}$ & $131,88 \mathrm{aB}$ & $149,42 \mathrm{bB}$ \\
\hline $1 / 2 E+1 / 2 R$ & $0,0155 \mathrm{a}$ & $0,0073 \mathrm{~b}$ & $0,0076 \mathrm{~b}$ & $206,80 \mathrm{bB}$ & $149,73 \mathrm{aC}$ & $263,93 \mathrm{aA}$ \\
\hline $1 / 3 \mathrm{E}+1 / 3 \mathrm{H}+1 / 3 \mathrm{~V}$ & $0,0132 \mathrm{a}$ & $0,0076 \mathrm{~b}$ & $0,0072 \mathrm{~b}$ & $155,91 \mathrm{cA}$ & $107,29 \mathrm{bB}$ & $133,75 \mathrm{bA}$ \\
\hline $1 / 3 \mathrm{E}+1 / 3 \mathrm{H}+1 / 3 \mathrm{R}$ & $0,0175 \mathrm{a}$ & $0,0087 \mathrm{a}$ & $0,0086 \mathrm{a}$ & $189,9 \mathrm{bA}$ & $112,9 \mathrm{bB}$ & $152,8 \mathrm{bA}$ \\
\hline $1 / 4 \mathrm{E}+1 / 4 \mathrm{H}+1 / 4 \mathrm{~V}+1 / 4 \mathrm{R}$ & $0,0080 \mathrm{a}$ & $0,0073 \mathrm{~b}$ & $0,0059 \mathrm{c}$ & $280,3 \mathrm{aA}$ & $147,8 \mathrm{aB}$ & $179,7 \mathrm{bB}$ \\
\hline
\end{tabular}

al. (2015a) por 30 dias, propiciando mudas de qualidade. Contudo, ramas de mandioca trituradas e compostadas por 30 dias não foram favoráveis à formação de mudas de bocaiuva (Costa et al., 2014) e baruzeiro (Costa et al., 2012), mesmo utilizando adubação química na formação das mudas. Mistura de 50\% de ramas de mandioca triturada e 50\% de vermiculita adubadas com 2,5 $\mathrm{kg}$ de superfosfato simples $\left(18 \%\right.$ de $\left.\mathrm{P}_{2} \mathrm{O}_{5}\right), 0,3$ $\mathrm{kg}$ de cloreto de potássio $\left(60 \%\right.$ de $\left.\mathrm{K}_{2} \mathrm{O}\right)$ e $1,5 \mathrm{~kg}$ de calcário dolomítico $(100 \%$ de PRNT), por metro cúbico de substrato, em que as ramas foram apenas secadas ao sol, propiciaram as melhores mudas de berinjela (Costa et al., 2011), assim como substrato contendo $20 \%$ de ramas de mandioca trituradas e secas ao sol por uma semana (revirada diariamente) e $80 \%$ de esterco compostado por 15 dias (Costa et al., 2013b). Portanto, a compostagem de ramas de mandioca é benéfica para produção de mudas de solanáceas.

As mudas com melhores características de diâmetro, fitomassas e índice de qualidade de Dickson foram formadas na estufa agrícola coberta com
Tabela 4. Continuação

\begin{tabular}{|c|c|c|c|}
\hline \multirow{2}{*}{ Substratos** } & \multicolumn{3}{|c|}{ Altura da muda (cm) } \\
\hline & Estufa & Sombrite $\mathbb{B}$ & Aluminet ${ }^{\circledR}$ \\
\hline $1 / 2 \mathrm{E}+1 / 2 \mathrm{H}$ & $5,78 \mathrm{aA}$ & $3,39 \mathrm{bB}$ & $3,34 \mathrm{bB}$ \\
\hline $1 / 2 \mathrm{E}+1 / 2 \mathrm{~V}$ & $3,96 \mathrm{dA}$ & $3,73 \mathrm{aA}$ & $3,31 \mathrm{bB}$ \\
\hline $1 / 2 E+1 / 2 R$ & $4,28 \mathrm{cA}$ & $3,93 \mathrm{aB}$ & $3,78 \mathrm{aB}$ \\
\hline $1 / 3 \mathrm{E}+1 / 3 \mathrm{H}+1 / 3 \mathrm{~V}$ & $5,30 \mathrm{bA}$ & $3,77 \mathrm{aB}$ & $3,35 \mathrm{bC}$ \\
\hline $1 / 3 \mathrm{E}+1 / 3 \mathrm{H}+1 / 3 \mathrm{R}$ & $4,43 \mathrm{cA}$ & $3,67 \mathrm{aB}$ & $3,59 \mathrm{aB}$ \\
\hline \multirow[t]{2}{*}{$1 / 4 \mathrm{E}+1 / 4 \mathrm{H}+1 / 4 \mathrm{~V}+1 / 4 \mathrm{R}$} & $4,15 \mathrm{dA}$ & $3,81 \mathrm{aB}$ & $3,43 \mathrm{bC}$ \\
\hline & \multicolumn{3}{|c|}{ Massa seca total (g) } \\
\hline $1 / 2 \mathrm{E}+1 / 2 \mathrm{H}$ & $0,0991 \mathrm{a}$ & $0,0481 \mathrm{~b}$ & $0,0482 \mathrm{~b}$ \\
\hline $1 / 2 E+1 / 2 V$ & $0,0609 \mathrm{~b}$ & $0,0445 \mathrm{~b}$ & $0,0492 \mathrm{~b}$ \\
\hline $1 / 2 E+1 / 2 R$ & $0,1119 \mathrm{a}$ & $0,0558 \mathrm{a}$ & $0,0579 \mathrm{a}$ \\
\hline $1 / 3 \mathrm{E}+1 / 3 \mathrm{H}+1 / 3 \mathrm{~V}$ & $0,1099 \mathrm{a}$ & $0,0520 \mathrm{~b}$ & $0,0501 \mathrm{~b}$ \\
\hline $1 / 3 \mathrm{E}+1 / 3 \mathrm{H}+1 / 3 \mathrm{R}$ & $0,0961 \mathrm{a}$ & $0,0586 \mathrm{a}$ & 0,0559 a \\
\hline \multirow[t]{2}{*}{$1 / 4 \mathrm{E}+1 / 4 \mathrm{H}+1 / 4 \mathrm{~V}+1 / 4 \mathrm{R}$} & $0,0638 \mathrm{~b}$ & $0,0499 \mathrm{~b}$ & $0,0415 \mathrm{c}$ \\
\hline & \multicolumn{3}{|c|}{ Frutos $\left(n^{0}\right)$} \\
\hline $1 / 2 \mathrm{E}+1 / 2 \mathrm{H}$ & - & - & - \\
\hline $1 / 2 E+1 / 2 V$ & $24,25 \mathrm{bA}$ & $19,00 \mathrm{aB}$ & $15,50 \mathrm{bB}$ \\
\hline $1 / 2 E+1 / 2 R$ & $24,38 \mathrm{bB}$ & $18,50 \mathrm{aC}$ & $30,25 \mathrm{aA}$ \\
\hline $1 / 3 \mathrm{E}+1 / 3 \mathrm{H}+1 / 3 \mathrm{~V}$ & $17,00 \mathrm{cA}$ & $13,13 \mathrm{bA}$ & $16,38 \mathrm{bA}$ \\
\hline $1 / 3 \mathrm{E}+1 / 3 \mathrm{H}+1 / 3 \mathrm{R}$ & $18,6 \mathrm{cA}$ & $13,9 \mathrm{bB}$ & $18,3 \mathrm{bA}$ \\
\hline $1 / 4 \mathrm{E}+1 / 4 \mathrm{H}+1 / 4 \mathrm{~V}+1 / 4 \mathrm{R}$ & $34,4 \mathrm{aA}$ & $17,6 \mathrm{aC}$ & $25,8 \mathrm{aB}$ \\
\hline
\end{tabular}

*Letras iguais minúsculas nas colunas e maiúsculas nas linhas, para cada parâmetro, não diferem entre si pelo Teste de Scott-Knott a 5\% de probabilidade (for each parameter, the same lowercase letters in columns and uppercase letters in rows do not differ by Scott-Knott, $5 \%$ ); $* * \mathrm{E}=$ esterco bovino (cattle manure); $\mathrm{H}=$ húmus de minhoca (earthworm humus); $\mathrm{R}=$ ramas de mandioca (cassava stems); $\mathrm{V}=$ vermiculita (vermiculite). 
filme de polietileno de baixa densidade em comparação com os outros ambientes avaliados (Tabela 1). A ambiência vegetal propiciada por este tipo de cobertura permitiu melhor adaptação da pimenteira, assim como observado por Costa et al. (2015a) para as mudas de tomate cereja, os quais verificaram maior diâmetro, maior fitomassa seca da raiz e índice de qualidade de Dickson da cultivar Pera Amarela, assim como maior índice de velocidade emergência e diâmetro do colo da cultivar Pêra Vermelha e diâmetro do colo, fitomassa seca da parte aérea, radicular, total e índice de qualidade de Dickson da cultivar Carolina.

Dentre os horários de coletas não houve diferenças consideráveis de temperatura e umidade entre os ambientes. Portanto, a produção das mudas de pimenteira ornamental que foi favorecida na estufa agrícola pode ser atribuída a outros fatores micrometeorológicos, os quais segundo Costa et al. (2012) podem ser luminosidade e radiação fotossintética ativa.

Assim como observado por Costa et al. (2015a), possivelmente, em períodos de maior volume de chuvas (janeiro no presente trabalho), o filme de polietileno propicia condições mais adequadas de proteção à formação de mudas de hortaliças, conforme verificado no presente estudo, uma vez que não ocorre excedente hídrico, que pode prejudicar o desenvolvimento inicial das mudas de pimenteira, bem como a formação do stand.

Avaliando o crescimento da cultivar Etna (Tabela 1), não foi possível avaliar as plantas oriundas do substrato $1 / 2 \mathrm{E}+1 / 2 \mathrm{H}$, pois as poucas plantas emergidas nesse substrato não sobreviveram, portanto, não se recomenda esta formulação para cultivo. O substrato composto de $1 / 2 \mathrm{E}+1 / 2 \mathrm{R}$ propiciou as maiores médias de número de frutos por planta em combinação com o ambiente aluminet ${ }^{\mathbb{B}}$.

As melhores médias de produção da cultivar Etna ocorreram nos ambientes estufa e aluminet ${ }^{\mathbb{R}}$, podendo ser indicados para cultivo na região de Aquidauana. As misturas de substratos que propiciaram os melhores resultados foram $1 / 2 \mathrm{E}+1 / 2 \mathrm{~V}$ e $1 / 2 E+1 / 2 R$, sendo indicado o uso de ambos quando o cultivo ocorrer no interior da estufa e a mistura $1 / 2 \mathrm{E}+1 / 2 \mathrm{R}$ quando utilizado o ambiente aluminet ${ }^{\mathbb{R}}$ (Tabela 1). Os bons resultados obtidos pelos substratos apresentam o efeito benéfico quando há mistura de materiais orgânicos em proporções corretas para formular o substrato, pois a combinação dos materiais disponibiliza maiores quantidades de nutrientes, retém maior quantidade de água e muitas vezes obtem-se os componentes da mistura no próprio local de produção. O cultivo no ambiente sombrite ${ }^{\circledR}$ apresentou as maiores temperaturas comparado com os ambientes protegidos como a estufa e a aluminet ${ }^{\mathbb{}}$; este fator pode ter contribuído para o maior abortamento floral e por consequência as menores médias de geração de frutos. Altas temperaturas podem causar perdas significativas na produção de muitas espécies, pela redução no número de sementes e aumento da abscisão das flores (Erickson \& Markhart, 2002).

O ambiente de cultivo estufa agrícola propiciou as melhores médias de crescimento para as avaliações de altura das plantas (Tabela 1). Tal fato pode ser explicado devido ao maior armazenamento de energia interna no ambiente, em função do filme de polietileno. Esta energia influi diretamente no metabolismo das plantas, resultando no maior crescimento das mesmas.

Holcman (2009), estudando a produção de tomate cereja em ambiente protegido (cobertura plástica difusora e anti-UV), verificou que há maior acumulo de radiação solar e radiação difusa no ambiente com plástico difusor, sendo que estas formas de energia são utilizadas pelas plantas na fotossíntese. Tal resultado contrasta com o obtido no presente trabalho pois, o ambiente estufa agrícola permitiu o desenvolvimento de mudas melhores.

\section{Cultivar ornamental Pirâmide}

Os substratos $1 / 2 \mathrm{E}+1 / 2 \mathrm{~V}, 1 / 3 \mathrm{E}+1 / 3 \mathrm{H}+1 / 3 \mathrm{~V}$ e $1 / 3 E+1 / 3 H+1 / 3 R$ propiciaram melhores condições de crescimento e formação das mudas (Tabela 2), ou seja, uma rápida formação do stand de plantas. Mudas com maiores diâmetros, fitomassas e índice de qualidade de
Dickson são provenientes dos substratos $1 / 2 \mathrm{E}+1 / 2 \mathrm{R}, 1 / 3 \mathrm{E}+1 / 3 \mathrm{H}+1 / 3 \mathrm{~V}$ e $1 / 3 \mathrm{E}+1 / 3 \mathrm{H}+1 / 3 \mathrm{R}$. Esses resultados se assemelham aos observados para a cultivar Etna no presente estudo (Tabela 1). A altura e a velocidade de emergência da planta conferem mudas mais resistentes ao estresse térmico e mais aptas ao transplante (Silva et al., 2011).

Assim como para cultivar Etna, as plântulas emergidas no substrato $1 / 2 \mathrm{E}+1 / 2 \mathrm{H}$ não sobreviveram, confirmando-se, portanto, que esta composição não é benéfica para produção de pimenteira ornamental. Avaliando-se a produção da pimenteira Pirâmide, verifica-se que as maiores médias de produção de frutos foram verificadas no substrato $1 / 2 \mathrm{E}+1 / 2 \mathrm{R}$ em combinação com o ambiente aluminet $^{\mathbb{}}$, assim como as combinações $1 / 3 \mathrm{E}+1 / 3 \mathrm{H}+1 / 3 \mathrm{~V}$ e $1 / 4 \mathrm{E}+1 / 4 \mathrm{H}+1 / 4 \mathrm{~V}+1 / 4 \mathrm{R}$ na estufa agrícola (Tabela 2).

Em relação aos ambientes de produção, bem como para cultivar Etna (Tabela 1), os ambientes estufa agrícola e aluminet ${ }^{\mathbb{B}}$ propiciaram as melhores condições para produção de mudas de pimenteira ornamental, cultivar Pirâmide (Tabela 2).

Desta forma, pode-se afirmar que na fase de formação das mudas o substrato indicado seria $1 / 3 \mathrm{E}+1 / 3 \mathrm{H}+1 / 3 \mathrm{R}$ o qual apresentou melhores resultados dos parâmetros estudados no ambiente de estufa agrícola. Para a fase de produção de frutos destacaram-se os substratos $1 / 3 \mathrm{E}+1 / 3 \mathrm{H}+1 / 3 \mathrm{~V}$ e $1 / 4 \mathrm{E}+1 / 4 \mathrm{H}+1 / 4 \mathrm{~V}+1 / 4 \mathrm{R}$ no ambiente estufa, embora a maior produção foi no ambiente aluminet ${ }^{\mathbb{R}} \mathrm{com}$ o substrato $1 / 2 \mathrm{E}+1 / 2 \mathrm{R}$.

\section{Cultivar Tupã Bode Vermelha}

O substrato composto $1 / 2 \mathrm{E}+1 / 2 \mathrm{R}$, o qual não diferenciou dos outros, apresentou rápida emergência (Tabela 3). Aponta-se que a maior velocidade de emergência de plântulas é importante para ter um stand bem formado em menor tempo, crucial na produção de mudas de hortaliças de elevada qualidade, fator verificado no presente estudo. Na comparação dos ambientes de cultivo, verifica-se que os melhores resultados de emergência foram no ambiente de estufa.

Maiores Índices de Dickson, 
fitomassas e diâmetros de mudas foram obtidos nas mudas produzidas nos substratos $1 / 2 \mathrm{E}+1 / 2 \mathrm{R}$ e $1 / 3 \mathrm{E}+1 / 3 \mathrm{H}+1 / 3 \mathrm{~V}$ (Tabela 3), sendo que este resultado é similar ao obtido para as cultivares ornamentais Etna (Tabela 1) e Pirâmide (Tabela 2). Estas misturas também beneficiaram a altura das plantas após o transplantio. Os melhores resultados estão em função do ambiente de estufa, corroborando com os resultados de Oliveira et al. (2014).

Maiores valores de produção e de número de frutos por planta foram verificados em pimenteiras produzidas nos substratos $1 / 3 \mathrm{E}+1 / 3 \mathrm{H}+1 / 3 \mathrm{R}$ e $1 / 2 \mathrm{E}+1 / 2 \mathrm{R}$, combinado com o ambiente de estufa e aluminet ${ }^{\circledR}$, respectivamente.

Assim foi possível observar que para a fase de formação de mudas os substratos $1 / 2 \mathrm{E}+1 / 2 \mathrm{R}$ e $1 / 3 \mathrm{E}+1 / 3 \mathrm{H}+1 / 3 \mathrm{~V}$ apresentaram melhor desempenho nos parâmetros avaliados, sendo o ambiente estufa com o filme de polietileno o mais adequado, corroborando com Costa et al. (2015b), seguido de sombrite ${ }^{\circledR}$ e aluminet $^{\circledR}$. Já na fase de produção dos frutos o substrato $1 / 2 \mathrm{E}+1 / 2 \mathrm{R}$ apresentou melhor desempenho sendo o ambiente estufa o mais indicado, seguido pelo aluminet $^{\circledR}$ e sombrite ${ }^{\circledR}$.

\section{Cultivar Boyra Habanero} Vermelha

Os parâmetros obtidos na fase de formação de mudas e produção estão em função do substrato e do tipo de ambiente protegido (Tabela 4).

A cultivar apresentou bom desempenho do índice de velocidade de emergência no uso do substrato $1 / 3 \mathrm{E}+1 / 3 \mathrm{H}+1 / 3 \mathrm{~V}$ vinculado ao ambiente de estufa. O substrato $1 / 2 \mathrm{E}+1 / 2 \mathrm{H}$ não é recomendado para o cultivo uma vez que as poucas plantas emergidas não sobreviveram na fase de produção de frutos, da mesma forma que ocorreu para as cultivares Etna, Pirâmide e Tupã.

$\mathrm{O}$ diâmetro do colo foi maior quando aplicados os substratos $1 / 2 \mathrm{E}+1 / 2 \mathrm{R}$ e $1 / 3 \mathrm{E}+1 / 3 \mathrm{H}+1 / 3 \mathrm{~V}$ no ambiente protegido de estufa e posteriormente de aluminet ${ }^{\circledR}$. Resultado similar foi obtido para a massa seca total e índice de qualidade de Dickson.

Em relação à fase de produção de frutos, a produção e o número de frutos foram satisfatórios para o substrato $1 / 4 \mathrm{E}+1 / 4 \mathrm{H}+1 / 4 \mathrm{~V}+1 / 4 \mathrm{R}$ no ambiente de estufa, e em segundo lugar o melhor substrato foi $1 / 2 E+1 / 2 R$ vinculado à instalação de aluminet ${ }^{\circledR}$. De maneira geral foi possível observar que para a cultivar Boyra na fase de formação de muda é mais aconselhado a utilização da estufa associado aos substratos $1 / 2 \mathrm{E}+1 / 2 \mathrm{R}$ e $1 / 3 \mathrm{E}+1 / 3 \mathrm{H}+1 / 3 \mathrm{~V}$, enquanto que para a fase de produção de frutos o substrato $1 / 4 \mathrm{E}+1 / 4 \mathrm{H}+1 / 4 \mathrm{~V}+1 / 4 \mathrm{R}$ é mais adequado para ambiente de estufa, seguido do substrato $1 / 2 \mathrm{E}+1 / 2 \mathrm{R}$ no sombrite ${ }^{\circledR}$ e aluminet ${ }^{\circledR}$.

Em síntese, a partir dos resultados obtidos na pesquisa foi possível concluir que para a produção de pimentas das cultivares Etna, Pirâmide, Tupã e Boyra o uso dos substratos $1 / 2 \mathrm{E}+1 / 2 \mathrm{R}, 1 / 3 \mathrm{E}+1 / 3 \mathrm{H}+1 / 3 \mathrm{R}$ e $1 / 3 \mathrm{E}+1 / 3 \mathrm{H}+1 / 3 \mathrm{~V}$ possibilitou maior diâmetro de colo, altura de planta e índice de qualidade de Dickson na fase de formação de mudas, enquanto que o número de frutos foi superior com a utilização dos substratos $1 / 2 \mathrm{E}+1 / 2 \mathrm{R}$ e $1 / 3 \mathrm{E}+1 / 3 \mathrm{H}+1 / 3 \mathrm{~V}$. O ambiente protegido de estufa foi o mais adequado para todas as cultivares, seguido pelo sombrite (Tupã e Boyra) e aluminet (Pirâmide).

\section{AGRADECIMENTOS}

Ao CNPq Proc. N $^{\circ} 300829 / 2012-4$ e à FUNDECT, proc. $n^{\circ}$ 23/200.647/2012 (Edital Chamada FUNDECT/CNPq ${ }^{\circ}$ 05/2011 - PPP - Programa Primeiros Projetos); CAPES.

\section{REFERÊNCIAS}

BANZATTO, DA.; KRONKA, SN. 2013. Experimentação agrícola. Jaboticabal: Funep. 247p.

COSTA, E; DURANTE, LGY; NAGEL, PL; FERREIRA, CR; SANTOS, A. 2011. Qualidade de mudas de berinjela submetida a diferentes métodos de produção. Revista Ciência Agronômica 42: 1017-1025.

COSTA, E; DURANTE, LGY; SANTOS, A; FERREIRA, CR. 2013b. Production of eggplant from seedlings produced in different environments, containers and substrates. Horticultura Brasileira 31: 139-146.

COSTA, E; JORGE, MHA; SCHWERZ, F; CORTELASSI, JAS. 2013a. Emergência e fitomassa de mudas de pimentão em diferentes substratos. Revista Brasileira de Ciências
Agrárias 8: 396-401.

COSTA, E; MARTINS, RF; FARIA, TAC.; JORGE, MHA; LEAL, PAM. 2014. Seedlings of Acrocomia aculeata in diferent substrates and protected environments. Engenharia Agrícola 34: 395-404.

COSTA, E; OLIVEIRA, LC; SANTO, TLE; LEAL, PAM. 2012. Production of baruzeiro seedling in different protected environments and substrates. Engenharia Agrícola 32: 633-641.

COSTA, E; PRADO, JCL; CARDOSO, ED; BINOTTI, FFS. 2015b. Substrate from vermiculite and cattle manure for ornamental pepper seedling production. Horticultura Brasileira 33: 163-167.

COSTA, E; SANTO, TLE; SILVA, AP; SILVA, LE; OLIVEIRA, LC; BENETT, CGS; BENETT, KSS. 2015a. Ambientes e substratos na formação de mudas e produção de frutos de cultivares de tomate cereja. Horticultura Brasileira 33: 110-118.

ERICKSON, AN; MARKHART, AH. 2002. Flower developmental stage and organ sensitivity of bell pepper (Capsicum annuum L.) to elevated temperature. Plant, Cell and Environment 25: 123-130.

FINGER, FL; RÊGO, ER; SEGATTO, FB; NASCIMENTO, NFF; RÊGO, MM. 2012. Produção e potencial de mercado para pimenta ornamental. Informe Agropecuário 33: 14-20.

GOMES, JM; COUTO, L; LEITE, HG; XAVIER, A.; GARCIA, SLR. 2003. Crescimento de mudas de Eucalyptus grandis em diferentes tamanhos de tubetes e fertilização N-P-K. Revista Árvore 27: 113-127.

GUIMARÃES, VF; ECHER, MM; MINAMI, K. 2002. Métodos de produção de mudas, distribuição de matéria seca produtividade de plântulas de beterraba. Horticultura Brasileira 20: 505-509.

HOLCMAN, E. 2009. Microclima e produção de tomate tipo cereja em ambientes protegidos com diferentes coberturas plásticas. Piracicaba: ESALQ. 127p. (Dissertação mestrado).

OLIVEIRA, FA; MEDEIROS, JF; LINHARES, PSF; ALVES, RC; MEDEIROS, A; OLIVEIRA, MK. 2014. Pepper seedlings production fertigated with various nutrient solutions. Horticultura Brasileira 32: 458-463.

RÊGO, ER; FINGER, FL; RÊGO, MM. 2012. Consumption of pepper in Brazil and its implicarions on nutrition and health of humans and animals. In: Peppers: Nutrition, Consumption and Health. Proceedings... New York: Nova Science Publishers. p.159-170.

RODRIGUES, ET; LEAL, PAM; COSTA, E; PAULA, TS; GOMES, VA. 2010. Produção de mudas de tomateiro em diferentes substratos e recipientes em ambiente protegido. Horticultura Brasileira 28: 483-488.

SILVA, AR; RÊGO, ER; CECON, PR. 2011. Tamanho de amostra para caracterização morfológica de frutos de pimenteira. Horticultura Brasileira 29: 125-129.

SILVA NETO, JJD; RÊGO, ER; NASCIMENTO, MF; SILVA FILHO, VAL; ALMEIDA NETO, JX; RÊGO, MM. 2014. Variabilidade em população base de pimenteiras ornamentais (Capsicum annuum L.). Revista Ceres 61: 84-89. 